\title{
People's Perspectives: Insights into Organ Donation from Brain Stem Dead Donors
}

\author{
Reeta Dar Khashu, Dr. Sunil Kumar Dar \\ *Health Education Officer at Central Health Education Bureau, DGHS, MOHFW, Govt. of India, New Delhi \\ **State RMNCH+A; Technical officer IPE Global, Dehradun, India
}

\begin{abstract}
This article gives us insights into the grey areas and conflicts surrounding organ donation from brain stem dead donors from the perspective of people in India. Brain stem death is a new definition of death which is not commonly understood. This article questions the recipient centric organ donation law given to understand the anti-therapeutic effect of apnea test on the donor, a prerequisite for diagnosing brain stem death. The articlealso voices concern overthe partial instructions given to donors or donor families, mistrusted medical fraternity, unregulated market of organ donation and altruism not percolating in the system.

It also deals with factors like Lazarus sign and body movements of the brain stem dead; non-acceptance of conditionaldonation and undisclosed identities of recipients post donation acting as dissuading factors in popularizing organ donation. Thearticle makes a strong case for developing common man's faith in the medial system and professionals and prevention of doctors from succumbing to the pressures to diagnose patients as brainstem dead. This article suggests making family consent for apnea test mandatory; giving the family an option to be present during the test and giving them the choice to say no to postmortem. The paper also suggests creating awareness on the new definition of death, the Law of organ donation and transplantation, disseminating comprehensive information, regularizing market, providing health related incentives to donor families, conducting research on people's perspective and allowing conditional donation of at least one organ.
\end{abstract}

Key Words; Brain Stem Death, People's perspective,THOA 1994, Organ donation

\footnotetext{
The organ donation from a brain stem dead person was made legal in 1994 with the enactment of the Transplantation of Human Organs Act (THOA) 1994. The Transplantation of Human Organs Act (THOA) 1994is meant to be a regulatory provision for removal, storage and transplantation of human organs for the therapeutic purposes and prevention of commercial dealings in human organs. Organ donation from a single brain stem dead donor can give life to seven persons by donating organs like two kidneys, liver,pancreas, heart ,two lungs and very rarely intestines(Dar Reeta and VivekAdhish 2014). India needs 2, 60,000 organs every year i.e., 1, 80,000 kidneys, 30,000 livers and 50,000hearts whereas only 6000 kidneys, 1200 livers and 15 hearts are transplanted annually (DGHS, NOTP, 2011). India having started National Organ Transplant Programme in 2009 has a long way to go in popularizing organ donation from brain stem dead donors which is not a simple task owing to a number of issues from peoples perspective as shown in Figure.1 below.;-
} 


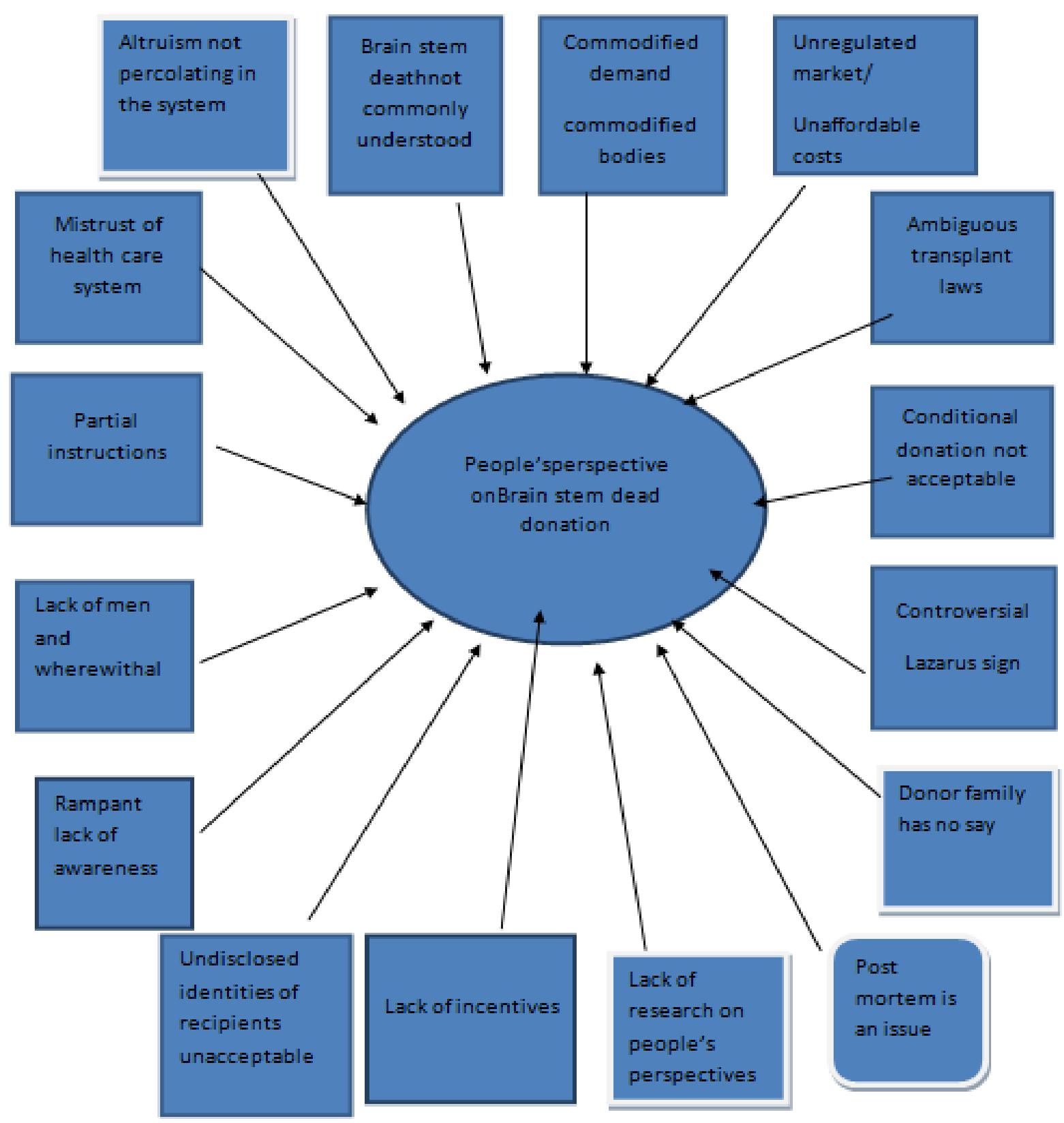

Figure.1 Showing People Centric Issues of Organ Donation from Brain Stem Dead Donors

\section{BRAIN STEM DEATH IS NOT COMMONLY UNDERSTOOD}

Brain death/brain stem death is a new definition of death not understood by many. A dead person for majority of people is the one who does not have pulse, respiration and does not make any movement. But this may not be true with brain stem death. In other words there are two kinds of death one is when whole body dies and people may not have any objection to such donation. Other is brain stem death or death of the brain but not of body as a whole which is not well understood .Many articles say that the process of organ donationtransplanting from a brain dead revolves around a person who is at the mercy of others. Opponents of organ transplant from brain dead persons (Slomka 1995; Youngner et al 1989; HauptW.F.andRudolf,J1999;Evans,D.W and Potts 2002) believe that brain dead persons are not completely dead persons. However, others believe that brain dead persons are dead persons (Paul St. MN 2001; Dosemeci L et al 2004). 


\section{AMBIGUOUS TRANSPLANT LAW}

The Transplantation of Human Organs Act (THOA) 1994 is an act allowing removal, storage and transplantation of human organs for therapeutic purposes and for the prevention of commercial dealings in human organs. The question arises; whose therapeutic purpose are we concerned with? Incising a live person in case of live donation who is not sick, removing his vital organ for the benefit of other isnot at all therapeutic to the donor. In case of brain stem death the tests especially the apnea test (Valko Nancy 2005) done on a patient to declare him brain stem dead, is anti-therapeutic to the medically compromised donor. The apnea test in fact aggravates the patient's condition (Joffe,A.R 2006).It requires deciding if the benefit to one or more individuals justifies the risk to another. The authors of this paper posed this question to the medical colleagues in JNU. The answer was that both recipient and donor should be considered for therapeutic benefit. The majority view was that the body of a donor is not an inanimate commodity and risk to donor, whether live or brain stem dead cannot be undermined by this interpretation of law.

\section{ALTRUISM A PRECONDITION FOR DONOR FAMILY NOT PERCOLATING IN THE SYSTEM}

The law bans sale of donated organs by the donor families but not the commercial activity at other levels. All those involved in the process - physicians, surgeons, coordinators, social workers, hospitals, etc.stand to gain commercially out of it especially in private hospitals. However the donor family does not stand to gain anything (Peters,T.G 1991).The private hospitals charge exorbitantly for transplant surgeries as was reported by many people during awareness programmes and are even reluctant to divulge the cost of transplant surgeries (ORGAN India 2014). This surely is unfair and insensitive and is bound to breed public distrust of the system.

\section{PARTIAL INSTRUCTIONS}

For the families willing to donate organs of their brainstem dead kin, it is surely not an easy task. They too face moral and ethical questions. The main one pertains to the expressed will of the brain stem dead person. He might not have been aware of the concept of brainstem death at the time of signing pledge form /donor card or giving an option in favor of organ donation in driving license. As such, there are no written instructions given to the potential donor or his family on the concept and the processes involved in organ donation from brainstem dead donor. At the moment, there is no legal binding to do so. In most of the cases, the donors are given partial or selective information. This can be checked from the available donor card/pledge forms available online.

In one case abroad, a 21-year-old man who had been declared legally dead but was on artificial life support had his organs harvested under court order over his family's objections. The mother felt that her son did not fully understand the choice he had made in the donor card. She expressed her anguish that the respirator and other machines were there to keep his body working and his organs healthy for donation and not for prolonging his life. She said the brain death was just a convenient way to facilitate the donation of those organs about which her son knew little. She cursed the hospital for robbing her son of his organs (Manning Alison 2013).Many a times celebrities like Bollywood actors are invited to endorse the cause of organ donation without giving proper information to them. It seems the celebrities are not even aware of the term brainstem death and perceive it as normal death. They pledge to donate organs thinking that the processes involved in organ donation are same as that of tissue donation like eye donation. They too support clarification of the process of the organ donation and emphasize it be made simpler. They also urge that utmost care needs to be taken to make the body look aesthetic and not mutilated. Dignity of body after donation needs to be assured ensured and facilitated (Gupta Priya2013).

\section{DONOR FAMILY HAS NO SAY}

The most ironical fact is that the family of the donor is not allowed to have a say in pronouncing their loved one brain dead. Under the existing laws, it is not mandatory to take the family's consent for conducting tests for declaring a person brainstem dead whereas mandatory choice in driving license in somestatesand mandatory request for asking families to donate organs has become the law. Professionals even recommend reducing the gap from 6 to 2 hours for repeat diagnosis of brainstem death a precondition for final diagnosis of brain stem death. The authors of this study say that in UK the time between the two sets of tests is discretionary and not time-bound (Seth Avinas Kumar et al 2009).

\section{CONTROVERSIAL LAZARUS SIGN}

The body of brain dead donors sometimes makes movements like living human beings. These movements make people think that the person is live and aware of surroundings. The review of 131 articles 
revealed a number of body movements that were considered to be spinal reflexes in brain dead patients(Saposnik et al 2009). The more frequently used were the plantar withdrawal responses (foot movements), muscle stretch reflexes, abdominal contractions, Lazarus's sign, and respiratory-like movements, among others in these articles. However the most startling and horrifying movements for family members is the 'Lazarus sign.' Lazarus sign convinces relatives that their loved one has come back to life. In this sign the arms of brain dead person rise up from the body, then draw in to the chest, ,sometimes crossing over the heart, then fall to the sides(ArkellInglis Esther2014). Proponents of the organ transplant claim that these movements originate from spinal cord neurons while relatives view these movements as signs of life. While some healthcare professionals say that these movements are no sign of life, for the relatives, the movements create confusion about the status of their loved one's life.

\section{MISTRUST OF HEALTHCARE SYSTEM}

People in general have mistrust on medical community that actually comes from their experiences with medical professionals (Dar Reeta and VivekAdhish2014). Medical diagnosis and prognosis have proved wrong for many people. This has come to the notice of one of the authors during the awareness programmes conducted by Central Health Education Bureau, Govt. of India on organ donation and transplantation. People feel doctors do unnecessary medical tests and ask for hefty consultation fees. In organ donation too, many people have come to know of doctors indulging in unfair practice. Here is a story to make the point. A young British man today owes his life to his insistent father. The father did not allow his son's organs to be removed, despite doctors telling him repeatedly that his son would not recover from the injuries suffered in a car accident (Hoffman Mathew Cullinan 2012). He recovered and is doing well.

\section{COMMODIFIED DEMAND, COMMODIFIED BODIES}

Today, when it comes to organ donation, unfortunately, instead of going into a phase of deep introspection and correction, we seem to be getting into projection. The science of transplant, it seems, has given us liberty to view a brainstem dead patient as treasure trove of organs. The entire discourse on organ donations is centered on people who may not be keen on organ donation since they do not stand to gain out of it. Besides, they may also feel guilty of handing over the 'body' of their dead one to doctors, whose heart is still beating.

The fact is that people who need organ transplants are dying because their own organs have failed and that the families of brainstem dead persons could give them a second chance to live.

Now instead of being persuasive and humble in approaching the families of the brain dead persons, who face a huge dilemma in accepting this new definition of death for their loved one, we tend to blame them for not donating organs. This narrative is universally quoted in research articles.

In fact, pressure is being put on the government to make brain death declaration mandatory (ORGAN India 2014)and go for presumed consent. This, in turn, may pressurize doctors for declaring a patient brainstem dead and public for donation. This can be hazardous for National Organ Transplant Programme given the prevalent corruption in healthcare system; poor doctor-patient relationship (Berger David 2014) and existing huge economic and social disparities in India. Government has to be cautious as transplant surgeries are mostly done in private hospitals and are affordable only by affluent people.

\section{POST MORTEM IS AN ISSUE}

India's proposed national organ sharing mechanism is facing a major roadblock in the form of mandatory post mortem. Doctors wonder as to why is post mortem needed in a clear case of road accident. They prefer to emulate the US system in which forensic doctors rely on the transplant surgeon's assessment. This is also to keep in mind that forensic doctors are generally busy professionals and may not be able to reach hospital in time (IyerMalathy 2013). It may also be noted that professional's fight over postmortem choices and it undermines wishes of the donor family. In most cases the family members may not like their brainstem dead relative to go through post mortem. They definitely would prefer donating his organs if given a choice. It shall be helpful if people in legal possession of body are given a lawful choice to opt for or against post mortem.

For this, one more columns in which people can tick the option of being subjected to post mortem or not in case of brainstem death can be added in the pledge forms or driving licenses.

\section{UNDISCLOSED IDENTITIES OF RECIPIENTS UNACCEPTABLE}

World over organ donors are never told of the identity of the recipient. During many felicitation events of donor families in India, it came out that the donor families always want to know who the recipients were. In those cases where people have come to know of the identities of the recipients, it has led to new relationships 
called biosocial relations. In such cases, the recipients have celebrated their rebirths with the donor families. In many countries including US the rule forbidding donor-recipient contact is breaking down. More and more recipients are finding out about their donor. Some have discovered it by following up the published obituaries of the days around their own 'rebirth'. The fact is that the donors are keen to find out the recipients and in the process institutional barriers are breaking down. Today, in the US Transplant Games are organized where the curious recipients and donors mingle and reach to each other and feel happy and contented (Transplant Games 2014).

\section{CONDITIONAL DONATIONSNOT PERMITTED}

The relatives of a deceased donor are sometimes adamant that the organs should be transplanted only on the white-skinned people, as was reported in U.K. Such instances have been reported in India too where people wanted to donate to people of their own religion. Such conditional donations are currently rejected. Wilkinson supports conditional donation and believes that conditional donation is not always wrong(Wilkinson T.M 2003).Selective acceptance of conditional brain stem dead donation of at least one organ may give meaning to donation from the perspective of people(Dar Reeta and Sunil Kumar Dar2014). Let these biological assets not go waste for flimsy reasons.

\section{UNREGULATED MARKET AND UNAFFORDABLE COSTS}

The transplant surgeries which are mostly done in private hospitals are not within the reach of every person requiring a transplant for fighting end stage organ failures. The cost of these transplant surgeries varies from hospital to hospital and is different for different organs. At the moment there are no checks on the cost of these surgeries. The cost of transplant surgeries like kidney transplant is 2-4 lack and liver transplant is 24 lacks as per the study (ORGAN India 2014) but a few families reported to the authors that they had paid more than 30 lacks for liver transplant. The hospitalsare also reluctant to disclose the exuberant transplant costs of these surgeries as has been recently quoted in a study on organ donation in India (ORGAN India 2014).

\section{LACK OF MEN AND WHEREWITHAL}

In linking poor donations to lack of awareness we often miss the point that there is a huge lack of infrastructure, material and manpower resources in the field of retrieval and transplantation of organs. Therefore we uselessly keep blaming people for low donation rates. India will have to do a lot of work to establish Regional Organ and Tissue Transplant Organization (ROTTO) and State Organ and Tissue Transplant Organization (SOTTO). The setting up the processes of retrieval and transplantation for different organs, transportation and allocation of organs, networking, and training of different types of manpower is a big job and is not going to be easy since health is a state subject. Besides integrating the work of all stakeholders including NGO'S in the field of organ donation and transplantation is a challenging task. However, National Organ and Tissue Transplant Organization (NOTTO) at Safdar Jang Hospital, New Delhi, has been set up and all efforts are on to make it fully functional.

\section{LACK OF INCENTIVES}

There are no incentives for donor families post donation (Dar Reeta 2014).In Israel, consent given by a person during his life to donate an organ following his death, accords both the person and his first degree relatives' priority in organ allocation. Further an organ donated by a person following his death accords his first degree relatives priority in organ allocation in Israel (Jacob Lavee et al 2009) as well as in Japan (K Aita 2011).During awareness programs by Central Health Education Bureau, Government of India, it was realized that those willing to be donors by pledging organs and tissues in pledge forms wanted priority in organ allocation. And in case they become brainstem dead donors, they wanted assurances on two counts. One was a health insurance for their parents and also the privilege of giving priority in organ allocation to their family members, in case of a need in future.

\section{LACK OF RESEARCH ON PEOPLE'S PERSPECTIVE}

The research on perspective of people has not been studied extensively in India. We tend to view organ donation as an isolated entity and blame people for not donating organs. Organ donation cannot be viewed in isolation. People usually can't view brain stem death of a loved one as actual death. This leads to their resistance towards organ donation. People may be in favor of organ donation but not in favor of brain stem dead donation as was found during pretesting of pledge form in context of THOA rules 2014. The author found that live 
donation is a more acceptable form of donation than donation after brain stem death. Given an option to donate organs people are more inclined to living donation, however to their own family members and facebook friends only. Donating and living was more acceptable than dying to donate. . Brain stem death was acceptable to very few people.

\section{RAMPANT LACK OF AWARENESS}

The public as well as professionals are equally unaware of new definition of death (Dar Reeta and VivekAdhish 2014). After passing THOA in 1994, a major survey was conducted to find out about the attitude of public towards organ donation in 1995-96 (ShroffS 1997). The survey, conducted on 5008 people, showed $72 \%$ of the population were willing to donate eyes and carry a 'Donor Card'; less than 50\% were willing to consider solid organ donation. About $74 \%$ of Hindus, $72 \%$ Christians and 58\% Muslims were willing to consider organ donation; however the concept of brain death was new to most of the people surveyed. A study (Mishra,P.Het al 2004) was conducted in major government and private hospitals of Delhi to find out the reason for Organ Transplant program not picking up. The study showed that the major reasons for poor performance of Organ Transplant program is lack of awareness among public.

\section{CONCLUSION;-}

1. While organ donation may have therapeutic effects on the recipient it is debatable as to what it means to the brainstem dead donor.

2. Medical hegemony should give way to the family-centric model of organ donation. Many people will develop trust in medical community if family participation is involved at various stages - from diagnosis of brain death. Let people accept or reject apnea test; have choice to be near bedside of the patient during the apnea test; let people have choice to ask for or say no to postmortem. Let people see how the organs have been allocated.

3. Positive people will usually accept organ donation. Having conducted a number of health awareness programmes, the authors have personal experience to make an observation that people who truly are helpful in life don't get influenced by debates and controversies and more often are willing to help someone through organ and tissue donation

4. This paper suggests creating awareness on the new definition of death, the Act and rules of organ donation and transplantation to professionals as well as people. Creating awareness like that of US through organization of transplant games at national level shall go a long way in popularizing organ donation in India.

5. It also moots the idea of giving proper and complete comprehensive information to people, conducting research on people's perspective, developing conducive system for organ retrieval and transplantation, regularizing market, proving health related benefits to donors and their families, allowing conditional donation of at least one organ and involving family participation.

\section{References}

[1]. THOA 1994 Transplantation of Human Organs Act, 1994. Central Act 42 of 1994, The Gazette of India, part II; section 3; sub section (i); Feb 4, 1995

[2]. Dar Reeta and Vivek Adhish( 2014). Debates and dilemmas of organ donation from Brain Stem Dead Bodies from the perspective of professionals .EIJMR , 1 (4) , Retrieved on 4 December 2014 from www.express-journal.com

[3]. Slomka, J. (1995). What do apple pie and motherhood have to do with feeding tubes and caring for the patient? Arch.Intern.MedJournal, vol.155, 1258-63.

[4]. Youngner Stuart .J, Claudia. J Coulton, Barbara, W Juknialis and Mark Leary (1989).Brain death and organ retrieval. A cross-sectional survey of knowledge and concepts among health professionals.Journal of American Medical Association, vol. 261, 2205-10.

[5]. Haupt, W.F and Rudolf, J.(1999) European brain death codes: a comparison of national guidelines. Journal of Neurology, 246(6), 432-7.

[6]. Evans, D.W. and Potts, M (2002).Brain death. British Medical Journal, 325(7364), 598.

[7]. Paul St. MN. (2001)Spontaneous movements often occur after brain death. Science Daily Science News, May 13. Retrieved on 23 December 2010from <www.sciencedaily. com/ releases/2000/01/000113080008.htm

[8]. Dosemeci L, Cengiz M, Yilmaz, M. and Ramazanoglu, A (2004).Frequency of spinal reflex movements in brain dead patients. Transplant Proceedings, 36(1) 17-19.

[9]. Valko Nancy, RN (2005). Should we be dying to donate? Women for Faith and Family; voices online edition 20(1), Retrieved on 14December 2011 from <http://www.wf-f.org/05-1-OrganDonation.html

[10]. Joffe, A.R (2006) Time dependent validity in the diagnosis of brain death using Trans cranial Doppler. Journal of Neurology, Neurosurgery and Psychiatry, vol.77, pp. 646-49.

[11]. Peters, T.G (1991): Life or death: The issue of payment in cadaveric organ donation. Journal of the American Medical Association, 265(10):1302-1305, 1991. 
[12]. Manning Alison. (2013).Family loses fight to keep son's organs from donation. The Columbus Despatch. Retrieved on16 May 2014 from <www.dispatch.com/.../Judge-ordered-family-to-let-brain-dead-son-donate.

[13]. Gupta Priya (2013).Kiran and Aamir pledge to donate their organs ,Times of India ;Gurgaon Times ,August 6,p.1

[14]. Seth Avinas Kumar et. al. (2009).First prospective study of brain stem death and attitude towards organ donation in India. Liver Transplantation, 15; 1443-47.

[15]. Saposnik, G. Basile, VS .and Young, G.B (2009) Movements in brain death: a systematic review. The Canadian Journal of Neurological Sciences, 36(2), 154-60.

[16]. ArkellInglis Esther(2014). The lazarus sign can convince you that brain dead people are alive ,Retrieved on 4 December 2014 from http://io9.com/the-lazarus-sign-can-convince-you-that-brain-dead-peopl-1500081143

[17]. Hoffman Mathew Cullinan (2012).Dad rescues brain dead son from doctors wishing to harvest his organs -boy recovers completely, Retrieved on 13 June 2014 from <www.lifesitenews.com/.../dad-rescues-brain-dead-sonfrom-doctors-wishi.

[18]. ORGAN India (2014).A study of the deceased organ donation environment in Delhi/NCR. An initiative of the Parashar Foundation in partnership with MOHAN Foundation. Outline India,

[19]. Berger David (2014).Corruption ruins doctor patient relationship in India. British medical journal;348:g3169 ,Retrieved on 1 December 2014 from < doi:10.1136/bmj.g3169

[20]. IyerMalathy(2013). New organ donation rules to hit forensic experts and families. Times of India 6.june 2013 p19

[21]. Transplant games of USA (2014). Retrieved on 24November 2014 from <http://www.transplantgamesofamerica.org/

[22]. Wilkinson T.M (2003). What's not wrong with conditional organ donation Med Ethics ,29:163-164, Retrieved on 5 May 2014 from <doi:10.1136/jme.29.3.163

[23]. Dar Reeta and Sunil Kumar Dar (2014).Pinnacle of Altruism Organ: Donation and Transplantation. EIJMR, 1 (6) Retrieved on 4 December 2014 from<www.express-journal.com

[24]. Dar Reeta (2014). Challenges to organ donation from brain stem dead persons in India. The Nursing Journal of India,Vol.CV (3),105-108

[25]. Jacob Lavee. Tamar Ashkenazi, Gabriel Gurman.\& David Steinberg (2009). A new law for allocation of donor organs in Israel Retrieved on 25May 2014 from www.The Lancet.com doi:10.1016/s0140-6736(09)61795-5

[26]. K .Aita( 2011, Mar 15).New organ transplant policies in Japan, including the family-oriented priority donation clause. Transplantation, 91 (5):489-91, Retrieved on 25May 2014from <doi:10.1097/TP.0b013e318205b3ab.

[27]. Shroff S (1997)The Antiseptic, vol.94, 73-74

[28]. Mishra P H, ArtiVij and R K Sharma (2004)A Knowledge, Attitude and Practice Study of Organ Donation and its Problems in the Metropolitan City of Delhi', Journal of the Academy of Hospital Administration, vol. 16, no. 1 ,pp.1-6. 